\title{
RESENHA CRÍTICA: THE EMOTIONAL ROLLERCOASTER OF LANGUAGE TEACHING
}

CRITICAL REVIEW: THE EMOTIONAL ROLLERCOASTER OF LANGUAGE TEACHING

\author{
Gysele da Silva Colombo Gomes', Flavio Barreto Soares² \\ 1 Universidade do Estado do Rio de Janeiro (UERJ), São Gonçalo, RJ, Brasil \\ http://orcid.org/0000-0002-1309-4312 \\ gysacolombo@uol.com.br \\ 2 Instituto Superior de Ciências Humanas e Sociais Anísio Teixeira, São Gonçalo, RJ, Brasil \\ https://orcid.org/0000-0002-7019-5101 \\ fbs1406@gmail.com
}

Recebido em 11 nov. 2021

Aceito em 23 nov. 2021

GKONOU, C.; DEWAELE, J.; KING, J. (ed.). The Emotional Rollercoaster of Language Teaching. Bristol: Multilingual Matters, 2020.

Os editores deste livro são Christina Gkonou, PhD em Ensino de Língua Inglesa e Mestra em Ensino de Inglês como Língua Estrangeira (Universidade de Essex, Reino Unido); Jean-Marc Dewaele, PhD em Língua e Literatura Francesas, Mestre em Francês e Espanhol, Mestre em Direito Europeu e Internacional e Mestre em Relações Internacionais com o Ocidente Europeu (Universidade Livre de Bruxelas); e Jim King, PhD e Mestre em Linguística Aplicada (Universidade de Nottingham).

Ao lançarmos nosso primeiro olhar sobre esta obra de 399 páginas, observamos o foco dado à complexidade emocional da atividade do ensino de línguas e como as emoções que os professores experimentam durante suas práticas podem representar uma verdadeira montanha russa emocional. O livro está baseado na premissa de que ensinar não trata apenas de transmitir conhecimento acadêmico, mas também de inspirar alunos; estabelecer conexões entre professores e alunos; e criar relacionamentos pedagógicos baseados em empatia, confiança e paciência. $O$ texto em si sugere que uma das formas mais importantes de o professor alcançar relações emocionais estáveis é compreendendo e convivendo de forma saudável com suas próprias emoções para poder proporcionar um ambiente emocionalmente saudável para seus alunos.

$\mathrm{Na}$ leitura desta antologia, como os próprios editores a denominam, somos levados de forma agradável ao encontro com 16 capítulos com média de 21 a 30 páginas cada, organizados de forma que nos sejam apresentados uma miríade de 
tópicos relacionados às emoções em sala de aula tanto positivas quanto negativas. Tratam-se de emoções relevantes à atividade de ensino de línguas, tais como: esforço emocional, burnout, regulação emocional, resiliência, inteligência emocional e bemestar, entre outras. Os tópicos são estudados em vários contextos como programas de formação de professores, ensino superior, CLIL (Content and Language Integrated Learning, em português: AICL - Aprendizagem Integrada de Conteúdo e Língua) e ambientes de pesquisa-ação, escolas primárias e secundárias em diferentes países.

Este livro é recomendado para qualquer aluno, pesquisador, professor ou formulador de políticas públicas que esteja interessado em pesquisar os aspectos psicológicos da atividade de ensino de línguas estrangeiras e que queira proporcionar condições saudáveis para o desenvolvimento do ensino e aprendizagem de línguas.

Podemos observar nesta obra que o tema trabalho emocional (HOCHSCHILD, $1983^{1}$ ) predomina nos capítulos escritos por: a) Kris Acheson e Robert Nelson; b) Sara Benesh; c) Peter de Costa, Wendy Li e Hima Rawal; d) Simon Humphries; e) Christina Gknou e Elizabeth. R. Miller. Ademais, questões como resiliência, poder, self (o eu), regulação de emoções, bem-estar, metáforas, ansiedade, psicologia positiva, e relações de poder no trabalho permeiam esta antologia tornando, dessa forma, os leitores em ávidos fãs da temática.

No capítulo de abertura, Gkonou et al. revisitam os estudos das emoções dos professores de línguas e delineiam a importância deste construto para a profissão hoje, seguida de uma breve descrição dos capítulos posteriores.

Nicole Hofstadler, Kyle Talbot, Sarah Mercer e Anitta Lämmerer, no segundo capítulo, intitulado "The Thrills and IIls of Content and Language Integrated Learning" (As emoções e os males da arendizagem integrada de conteúdo e língua) discutem os resultados de uma pesquisa sobre como professores austríacos trabalham com CLIL. Os autores debruçam-se sobre como o bem-estar pessoal desses professores e como o trabalho com CLIL afeta suas emoções através de um levantamento dos aspectos positivos, negativos e ambíguos desta atividade.

O terceiro capítulo, "Utilising the Emotional Labour Scale to Analyse the Form and Extent of Emotional Labour among Foreing Language Teachers in the US Public

\footnotetext{
${ }^{1}$ HOCHSCHILD, A. R. The managed heart: commercialization of human feeling. Berkeley, University of California Press, 1983.
} 
School System" (Utilizando a escala de trabalho emocional para analisar a forma e extensão do trabalho emocional entre professores de língua estrangeira no sistema de escolas públicas dos EUA) contém aproximadamente 30 páginas. O estudo pautase pela escala de esforço emocional desenvolvida pela socióloga Arlie Hochschild. Os autores Kris Acheson e Robert Nelson dedicam-se à investigação do nível de esforço emocional em professores de línguas estrangeiras do estado da Geórgia.

No quarto capítulo, "Theorising Emotions from a Critical Perspective: English Language Teachers' Emotion Labour when Responding to Student Writing" (Teorizando as emoções sob uma perspectiva crítica: O trabalho emocional de professores de inglês ao responder à escrita do aluno), Sara Benesch explora o que e de que forma as emoções e as relações de poder se interconectam no ensino de língua inglesa. Para isso, ela entrevista professores de língua inglesa de uma universidade americana acerca das atividades e condições em suas práticas que podem ser consideradas como catalisadores de carga emocional, mais especificamente quando avaliam os trabalhos de seus alunos.

No quinto capítulo, somos atraídos pela narrativa eloquente de Emily Edwards e Anne Burns, que investigam as experiências emocionais dinâmicas de professores de línguas em uma pesquisa-ação. Em “Opening Pandora's Box': Language Teachers' Dynamic Emotional Experiences of Conducting Action Research" (Abrindo a caixa de Pandora: experiências emocionais dinâmicas de condução de pesquisa-ação de professores de língua), deparamo-nos com um olhar cuidadoso sobre o processo de formação de identidades de professores durante um programa nacional de pesquisaação através da análise das metáforas construídas nas entrevistas de cinco professores de inglês como segunda língua na Austrália.

Achilleas Kostoulas e A. Lämmerer devotam-se a entender como é construída a resiliência de professores de línguas no capítulo 6 . Sua pesquisa envolve dois professores em formação inicial na Áustria. Em "Resilience in Language Teaching: Adaptive and Maladaptive Outcomes in Pre-Service Teachers" (Resiliência no ensino de línguas: resultados adaptativos e desadaptativos em professores em formação)podemos entender, entre outras coisas, que os níveis de ansiedade e resiliência dos participantes não é estável e nem independente do contexto no qual são analisados; e, que iniciativas como cursos de atualização podem ajudar a mitigar os altos níveis de ansiedade para professores menos experientes, assim como uma 
carga menor de trabalho administrativo pode ter o mesmo efeito em professores mais experientes.

No capítulo 7, o autor Joseph Falout tem como objetivo propor novos métodos de pesquisa para ajudar a análise dos diferentes "selfs" do passado em "Past L2 Selves, Emotions and Classroom Group Dynamics: The Don't Ask, Can't Tell Policy" (Os eus passados, as emoções e as dinâmicas de grupo de sala de aula). Neste estudo, Falout nos mostra que a identidade profissional de professores de línguas pode ser investigada não só em relação à suas experiências passadas, mas também através das interpretações que estes profissionais fazem a respeito dessas experiências.

Em 'Critical Incidents' in Language Teachers' Narratives of Emotional Experience" (Incidentes críticos nas narrativas de experiência emocional de professores de língua), oitavo capítulo do livro, Christina Gknou e Elizabeth R. Miller analisam os depoimentos de professores de inglês em seis programas de ensino superior nos Estados Unidos e no Reino Unido, com o objetivo de entender incidentes críticos ao longo de suas carreiras e como estes professores interpretaram os efeitos dessas experiências emocionais criando significado para estes eventos de forma retrospectiva.

No nono capítulo, Simon Humphries propõe um retorno aos dados de sua pesquisa realizada com quatro professores de inglês japoneses, que trabalham em um curso superior de engenharia. Destaca-se em "Please, Teach Me How to Teach" (Por favor, ensina-me como ensinar) uma perspectiva de trabalho emocional, auto reflexiva, post hoc, na qual o autor revisita os dados de um dos professores da pesquisa anterior com a finalidade de identificar possíveis falhas durante a coleta de dados. Este capítulo além de relatar um caso intrínseco, no qual surgiram problemas durante as observações e entrevistas, revela que participantes podem atribuir a seus entrevistadores papel de terapeuta. O autor declara não estar preparado para preencher essa função e salienta a necessidade de mais publicações que explorem essa área pouco pesquisada.

Além de ser descrita como um dos principais temas no que se concerne aos estudos sobre as emoções, a ansiedade, foco do capítulo 10, tem sido apontada como um dos fatores que mais negativamente interfere no processo de ensinoaprendizagem de línguas estrangeiras (KRASHEN 1980; HORWITZ, 1986, 2010). 
Maiko Ikeda, Osamu Takeuchi e Hiroyuki Imai buscam retratar a forma como a ansiedade é percebida por professores de inglês como língua estrangeira ou segunda língua ao longo do tempo. Para isso, os autores discorrem sobre as mudanças da percepção de ansiedade de quarenta e dois professores japoneses do ensino fundamental prestes a começar a ensinar inglês num curso específico para tratar do tema ansiedade. Em "Investigating Dynamic Changes in Elementary School Teachers' Anxiety when Teaching English" (Investigando as mudanças dinâmicas na ansiedade de professores do ensino fundamental no ensino de inglês) encontram-se destacados os fatores envolvidos na mudança de percepção das emoções dos participantes.

No capítulo 11, Sam Morris e Jim King investigam como se dá o processo de regulação das emoções em professores de línguas. Para isso, eles realizam um projeto exploratório com professores universitários japoneses para entender de que forma eles regulam suas emoções e por qual motivo. O texto "Emotion Regulation among University EFL Teachers in Japan: The Dynamic Interplay between Context and Emotional Behaviour" (A regulação da emoção entre professores universitários de EFL no Japão: a interação dinâmica entre o contexto e o comportamento emocional) desafia o leitor a refletir sobre a habilidade de regularmos nossas emoções diante à complexidade do meio social e das emoções.

No duodécimo capítulo, o trabalho emocional de dois professores de inglês em escolas públicas no Nepal é o foco de P. Costa, W. Li e H. Rawal, que investigaram a relação entre o trabalho emocional desses profissionais e os fatores que os levaram à exaustão emocional. "Should I Stay or Leave? Exploring L2 Teachers' Profession from an Emotionally Inflected Framework" (Deveria ficar ou ir embora? Explorando a profissão de professores de uma perspectiva teórica emocionalmente modulada), nos revela como fatores macro (sociedade) e meso (comunidade e a escola) influenciaram o processo que conduziu esses professores a um estado de exaustão, inclusive, levando um dos pesquisados a desistirem da profissão.

No capítulo 13, a psicologia positiva destaca-se como a teoria do trabalho de Tammy Gregersen e Peter D. Macintyre e Nicole Macmillan. Os autores investigam o efeito de uma técnica da psicologia positiva chamada "Encontrando o Lado Bom", uma estratégia de ressignificação de situações que se propõe a diminuir alguns dos efeitos negativos do estresse. Para isso, eles usaram esta técnica diariamente por uma 
semana com uma professora americana lecionando no Oeste da África. "Dealing with the Emotions of Teaching Abroad: Searching for Silver Linings in a Difficult Context (Lidando com as emoções do ensino: procurando pelo lado bom que pode existir em uma situação ruim de um contexto difícil) nos permite concluir que a técnica de achar o lado bom em situações sobre as quais temos pouco ou nenhum controle pode ser uma boa estratégia. No entanto, é de extrema importância que identifiquemos o melhor procedimento de intervenção para cada caso.

Rebecca Oxford, no capítulo 14, apresenta diversos tópicos relacionados ao tema do bem-estar dos professores de línguas, tais como: empatia, inteligência emocional, regulação das emoções e esforço emocional. Em "The Well of Language Teachers' Emotional Well-Being" (O bem do bem-estar emocional de professores de língua), Oxford apresenta cinco estudos de caso baseados em entrevistas suas que usa para identificar as emoções apresentadas pelos professores pesquisados em suas narrativas. O estudo nos mostra que o bem-estar desses profissionais é construído a partir tanto de experiências interpretadas como positivas pelos participantes quanto daquelas interpretadas como negativas.

A relação entre a motivação de professores de inglês e fatores, tais como: sua proficiência na língua, tempo de experiência, gênero, idade e seu status na língua (primeira ou segunda) é o tema o do capítulo 15, escrito por Jean-Marc Dwaele. Num estudo quantitativo intitulado "What Psychological, Linguistic and Sociobiographical Variables Power EFL/ESL Teachers' Motivation?” (Quais variáveis psicológicas, linguísticas e sociobiográficas reforçam a motivação de professores de inglês como língua estrangeira, ILE/ inglês como segunda língua- ISL?) temos como instrumento para coleta de dados um questionário online de acesso irrestrito e sem identificação dos respondentes, em que o autor reúne 513 respostas para investigar a relação entre motivação e fatores como: o nível de inteligência emocional desses profissionais, sua proficiência no idioma, seu tempo de experiência em sala de aula, seu gênero, sua idade e o status do inglês (primeira ou segunda língua).

Gkonou, Dewaele e King apresentam no último capítulo suas conclusões acerca dos diversos artigos apresentados ao longo dos capítulos, destacando o impacto que estas pesquisas têm nas práticas em sala de aula e na formação dos professores. Os autores asseveram que estes impactos não afetam somente professores, mas sim, 
todos os envolvidos no processo de ensino-aprendizagem tais como alunos e pais. Além disso, alegam que esses efeitos não são momentâneos e podem afetar várias gerações. Por fim, reforçam a necessidade de se continuar investigando as emoções dos professores.

\section{Sobre os autores}

\section{Gysele da Silva Colombo Gomes}

Doutora em Estudos da Linguagem pela Pontifícia Universidade Católica do Rio de Janeiro (2014), graduada em Letras Português- Inglês pela Universidade do Estado do Rio de Janeiro (1990), mestre em Linguística Aplicada pela Pontifícia Universidade Católica de São Paulo (2006) e pós-doutorada pela Universidade Federal de Viçosa. Professora adjunta da Universidade Estadual do Rio de Janeiro (UERJ), tem experiência na área de Letras, com ênfase em Língua Inglesa e Linguística Aplicada atuando principalmente nos seguintes temas: ensino de línguas estrangeiras; a Zona de Conforto; competências do professor de LE; ensino aprendizagem de LI, crenças, emoções, interação e autonomia na sala de aula; discurso e práticas sociais; alinhamentos, identidades e trabalhos da face; Prática Exploratória. É pesquisadora nos grupos Linguagem \& Sociedade (UERJ); Crenças e Emoções (UFV); e Núcleo de Estudos e Pesquisas em Prática Exploratória da FFP - UERJ.

\section{Flavio Barreto Soares}

Mestre em Letras (Linguagem e Ensino), MBA em Gerenciamento de Projetos, Programa de Desenvolvimento de Dirigentes Fundação Dom Cabral, Pós-Graduado em Língua Inglesa. Graduado em Letras Inglês/Literaturas de Língua Inglesa. Experiência em aulas para diversos segmentos e faixas etárias, supervisão e capacitação de professores, elaboração e avaliação de materiais, pesquisas editoriais, gerenciamento de carteira de clientes, treinamento de equipe de vendas, promoção e implementação de programas educacionais. 